\title{
DIMENSIONAMIENTO INTEGRADO DE SECCIONES SUJETAS A MOMENTOS FLECTORES Y ESFUERZOS CORTANTES PARA CONCRETOS DE ALTA RESISTENCIA
}

\section{Francisco Aguirre Torrico}

\section{RESUMEN}

Este trabajo está orientado al dimensionamiento integrado de elementos sujetos al esfuerzo cortante y momento flector de secciones rectangulares de hormigón de alta resistencia (HAR). Se presenta la Teoría del Campo de Compresión Diagonal Modificada, en la cual se permite el cálculo de elementos sujetos a tensiones normales y tangenciales de hormigón armado de una manera integrada. Además permite considerar las condiciones de equilibrio, de compatibilidad de deformaciones específicas y las relaciones constitutivas en términos de las tensiones y las deformaciones específicas medias. Para el cálculo de las secciones está siendo considerado el diagrama tensión-deformación específica realista de la norma EUROCODE 2 (2004).

El HAR fisurado da las bielas comprimidas es considerado como un nuevo material, su diagrama tensióndeformación específica es afectado por un factor de debilitamiento que disminuye su resistencia a compresión.

Palabras Clave: Hormigón de Alta Resistencia, Esfuerzo Cortante, Momento Flector, Dimensionamiento Integrado. 